\title{
Pattern of Congenital Overt and Occult Pediatric Surgical Anomalies in a Tertiary Care Centre Over 5 Years
}

\author{
Sam Varkey ${ }^{1}$, Aravind C. S ${ }^{1}$, Reeti Rajan² \\ ${ }^{1}$ Associate Professor, Department of Pediatric Surgery, Government Medical College Trivandrum, \\ Kerala, India. \\ ${ }^{2}$ Assistant Professor, Department of Obstetrics \& Gynecology, Government Medical College Trivandrum, \\ Kerala, India
}

Corresponding Author: Sam Varkey

\section{ABSTRACT}

Congenital anomalies are important cause of infant and childhood deaths, chronic illness and disability. The proportion of deaths and disability due to congenital anomalies has increased, as deaths due to other diseases have decreased over the years due to better health care. Hence it is essential to have basic epidemiological information of these anomalies. This is a hospital based, cross-sectional, record based study, conducted in the Department of Pediatric Surgery, Govt. Medical College Thiruvananthapuram, Kerala. Sample size included 300 children below the age of 12years admitted in the department of pediatric surgery with various major congenital anomalies, over a period of 5 years.

More than half of these children were admitted after infancy for treatment, male children were more compared to females. Majority of these children were from low socioeconomic group. Only in $5.6 \%$ cases there was a history of consanguineous marriage. In $7.33 \%$ there was family history of congenital anomalies. In 32\% cases the anomalies were detected in the antenatal period. Most of the anomalies were isolated anomalies. Genitourinary system was the most common system to be involved followed by, gastrointestinal tract. 91.67\% children underwent surgical treatment, and only $10.67 \%$ children had major complications in postoperative period.

This study shows that congenital anomalies are a major cause of hospital admissions in children of all ages. Pattern of anomalies seen in various centers are different. Knowledge of the pattern
\end{abstract}

of congenital anomalies may be useful in planning health services.

Keywords: Congenital, Anomalies, Pediatric surgery

\section{INTRODUCTION}

A congenital anomaly may be defined as, any irreversible condition existing in a child before birth in which there is sufficient deviation in the usual number, size, shape, location or inherent character of any part, organ, cell or cell constituent to warrant its designation as abnormal. [1] These anomalies occurring during intrauterine life may be identified prenatally, at birth, or sometimes may only be detected later in infancy. Although the cause of congenital anomalies may be multifactorial due to genetic, infectious, nutritional or environmental factors, it is often difficult to identify the exact causes.

Congenital anomalies are important cause of infant and childhood deaths, chronic illness and disability. An estimated 295000 newborns die within 28 days of birth every year worldwide due to congenital anomalies. [2] Congenital anomalies affect approximately 1 in 33 infants and result in approximately 3.2 million birth defect related disabilities every year ${ }^{[3]}$. It accounts for $8 \%$ to $15 \%$ of perinatal deaths and $13 \%$ to $16 \%$ of 
neonatal deaths in India ${ }^{[4,5]}$. Congenital anomalies may be divided into major and minor anomalies. Major anomalies interfere considerably with the function of all or part of the infant, minor malformation gives no serious medical or cosmetic consequences to the patient. The birth of an infant with major malformations, whether diagnosed antenatal or not, is emotionally traumatic to the parents.

Birth defects account for a significant proportion of morbidity and mortality among infants and children. With better mother and child health services and prevention of infections, infant mortality due to more common causes has been reduced, but the proportion of deaths due to congenital anomalies has increased. Hence it is essential to have basic epidemiological information of these anomalies, which may be useful in planning health services.

\section{METHOD}

This is a hospital based, retrospective, cross-sectional, record-based study. The study was conducted in the Department of Pediatric Surgery, Govt. Medical College Thiruvananthapuram, which is a tertiary care centre in Thiruvananthapuram district of Kerala. The study population included patients below 12 years of age, admitted in the Department of Pediatric Surgery with various congenital anomalies for a period of 5 years from January2016 to December2020. Minor anomalies were excluded.

Required sample size 291 was calculated using the formulae, $\mathrm{N}=4 \mathrm{pq} / \mathrm{d}^{2}$ where, $\mathrm{p}$ is prevalence, $\mathrm{q}=100-\mathrm{p}, \mathrm{d}$ is precision. $\mathrm{P}=3, \mathrm{q}=97, \mathrm{~d}=2$. The above values were calculated by going through existing data in Indian population. ${ }^{[6]}$

The sample size taken for the study was 300 , by random sampling method. Data was collected from the hospital records using a proforma. The variables like age, sex, birth weight, maternal age at delivery, consanguinity, gestational age at delivery, socioeconomic status, family history of congenital anomalies, mode of delivery, place of delivery, antenatal detection, nature of anomaly, system involved, number of surgeries and postoperative complications were recorded. Data collection and statistical analysis was done using KoBoToolbox statistical software.

\section{RESULT}

Out of 300 children, 54(18\%) were admitted in the newborn period, 76(25\%) during infancy and remaining 170(56.6\%) children after infancy. Even though the mean age of children admitted during the newborn period was 5.31days, most of the newborns were admitted at postnatal day1. Mean age of children admitted during infancy was 5.43months and the mean age of children admitted after infancy was 3.72years. Male children 223(74.33\%) were more affected compared to female $77(25.67 \%)$. Average birth weight of these children was 2.25kgs. Majority of them $270(90 \%)$ were from low socioeconomic background

Average maternal age at the time of delivery was 24.10years (median 24yrs). Only $17(5.66 \%)$ cases had history of consanguineous marriage. The mean gestational age at delivery was 39weeks.Most of the children 223(74.33\%) were delivered in non tertiary care centre and $77(25.67 \%)$ children were delivered in a tertiary care centre. 269(89.67\%) children were born through normal vaginal delivery, 26(8.67\%) through caesarean section and $5(1.67 \%)$ by assisted vaginal delivery.

In 22(7.33\%) children there was family history of congenital anomalies.

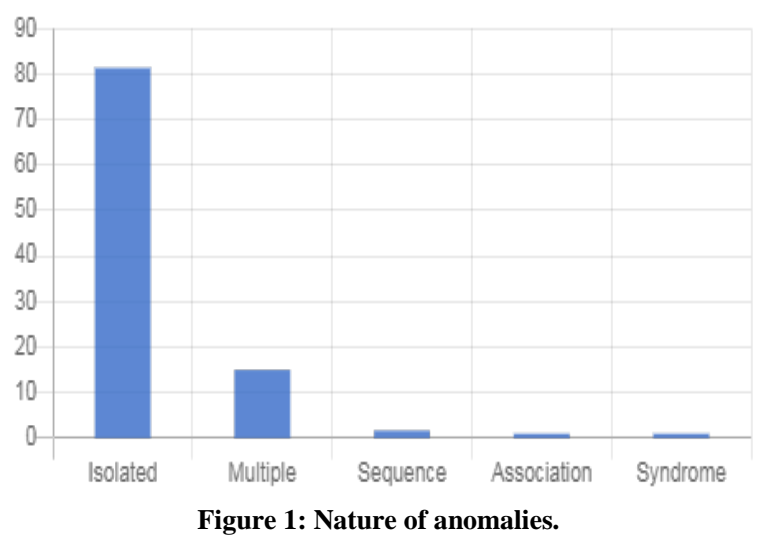


Sam Varkey et.al. Pattern of congenital overt and occult pediatric surgical anomalies in a tertiary care centre over 5 years.

In $96(32 \%)$ children the anomalies were detected in the antenatal period. In 244(81.33\%) children the anomalies were isolated anomalies. In 45(15\%) children there were multiple anomalies and in 11(3.67\%) children the anomalies were a part of sequence, syndrome or association, as shown in figure1.

System wise involvement of congenital anomalies is shown in table 1.

Table 1: Systems involved

Table 1: Systems involved
\begin{tabular}{|l|l|l|}
\hline Systems, n=300 & Frequency & Percentage \\
\hline Genitourinary & 159 & 55 \\
\hline Gastrointestinal & 77 & 25.67 \\
\hline Head \& neck & 44 & 14.67 \\
\hline Respiratory tract & 19 & 6.33 \\
\hline musculoskeletal & 1 & 0.33 \\
\hline
\end{tabular}

Out of 159 children with genitourinary anomalies, the types of genitourinary anomaly are shown in table-2

Table 2: Genitourinary anomalies

\begin{tabular}{|l|l|l|}
\hline Genitourinary anomalies, $\mathbf{n}=\mathbf{3 0 0}$ & Frequency & Percentage \\
\hline Ureteropelvic junction obstruction & 45 & 15 \\
\hline Vesicoureteric reflux & 32 & 10.66 \\
\hline Posterior urethral valve & 25 & 8.33 \\
\hline Hypospadias & 19 & 6.33 \\
\hline Undescended testis & 17 & 5.66 \\
\hline Renal duplex system & 5 & 1.66 \\
\hline Ureterocoele & 4 & 1.33 \\
\hline Congenital megaureter & 4 & 1.33 \\
\hline Exstrophy epispadias complex & 3 & 1 \\
\hline Disorders of sexual differentiation & 2 & 0.66 \\
\hline Multicystic dysplastic kidney & 2 & 0.66 \\
\hline Crossed fused ectopia & 1 & 0.33 \\
\hline
\end{tabular}

Out of 77 children with gastrointestinal tract anomalies, types of anomalies that were seen are shown in Table 3.

Table 3: Gastrointestinal anomalies

\begin{tabular}{|l|l|l|}
\hline Gastrointestinal anomalies, $\mathbf{n = 3 0 0}$ & Frequency & Percentage \\
\hline Anorectal malformations & 36 & 12 \\
\hline Hirschsprung's Disease & 13 & 4.33 \\
\hline Malrotation & 11 & 3.66 \\
\hline Annular pancreas & 4 & 1.33 \\
\hline Duodenal atresia & 3 & 1 \\
\hline Choledochal cyst & 3 & 1 \\
\hline Duplication cyst & 3 & 1 \\
\hline Patent Vitellointestinal duct & 2 & 0.66 \\
\hline Exomphalos & 2 & 0.66 \\
\hline
\end{tabular}

Anorectal malformations (ARM) were the predominant anomaly seen among children with gastrointestinal anomalies, the distribution based on the level of ARM as high, intermediate and low are shown in the figure 2. Out of 36 children with ARM, 17 were male and 19 females. 5male children had high ARM, 7 had intermediate, and 5 had low ARM. Among the female children, 1 had high ARM, 8 had intermediate, 7 had low ARM and 3 had cloacal anomaly.

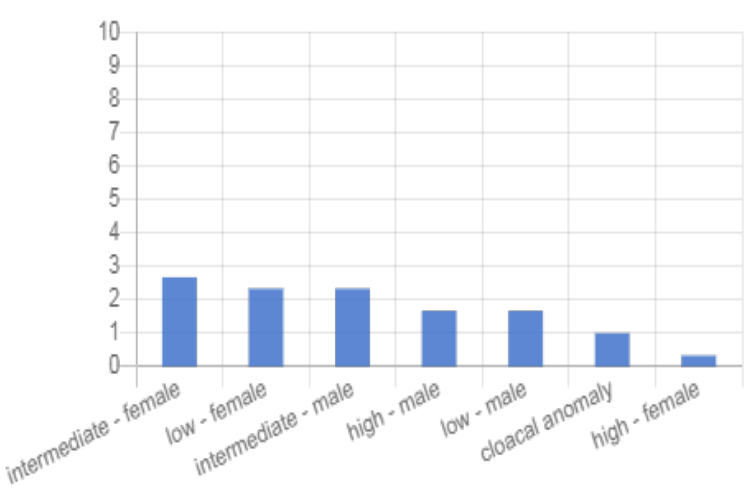

Figure 2: Anorectal malformations.

Out of the 44 children admitted with anomalies of head and neck, the types of anomalies are as shown in table 4.

Table 4: Anomalies of head and neck.

\begin{tabular}{|l|l|l|}
\hline $\begin{array}{l}\text { Anomalies of head and neck, } \\
\mathbf{n = 3 0 0}\end{array}$ & Frequency & Percentage \\
\hline Cleft lip and palate & 36 & 12 \\
\hline Cystic hygroma & 4 & 1.3 \\
\hline Choanal atresia & 2 & 0.6 \\
\hline Branchial cyst & 2 & 0.6 \\
\hline
\end{tabular}

Of the 19 children with respiratory tract anomalies the distribution of these anomalies is as in table 5.

Table 5: Anomalies of the respiratory tract.

\begin{tabular}{|l|l|l|}
\hline $\begin{array}{l}\text { Respiratory tract anomalies, } \\
\text { n=300 }\end{array}$ & Frequency & Percentage \\
\hline Congenital diaphragmatic hernia & 10 & 3.3 \\
\hline $\begin{array}{l}\text { Esophageal atresia, trachea- } \\
\text { esophageal fistula }\end{array}$ & 3 & 1 \\
\hline Eventration diaphragm & 2 & 0.6 \\
\hline Bronchopulmonary sequestration & 1 & 0.3 \\
\hline $\begin{array}{l}\text { Congenital pulmonary airway } \\
\text { malformation }\end{array}$ & 1 & 0.3 \\
\hline Congenital lobar emphysema & 1 & 0.3 \\
\hline Lymphangioma chest and axilla & 1 & 0.3 \\
\hline
\end{tabular}

275(91.67\%) out of 300 children underwent surgical treatment and 25(8.33\%) children were managed conservatively. 177(59\%) children had single surgery and 98(32.67\%) children had multiple surgeries. 207(69\%) children had no surgical complications, 36(12\%) children had minor complications and 32(10.67\%) children had 
Sam Varkey et.al. Pattern of congenital overt and occult pediatric surgical anomalies in a tertiary care centre over 5 years.

major complications in the post operative period.

\section{DISCUSSION}

There was a preponderance of anomalies in males compared to females. This was seen in similar studies. ${ }^{[7]}$ Reasons for male preponderance may be some anomalies of genitourinary tract are seen only in the male child e.g. hypospadias, undescended testes. The better care of a male child as compared to the female in India.

Average birth weight of babies in our study was $2.25 \mathrm{~kg}$; various studies have shown that the congenital anomaly rate for babies of low birth weight (2.5kg or less) was about $21 / 2$ times as high as that for heavier babies. ${ }^{[8]}$

Majority of the anomalies were seen in low socioeconomic group, this was also seen in other studies, where the risk of non chromosomal anomalies was higher in low socioeconomic group. ${ }^{[9]}$

We found consanguinity in $5.66 \%$ of cases in this study, which is slightly higher than the incidence of consanguinity (4.5\%) seen in the general population of Kerala. ${ }^{[10]}$ In our study the average age of mothers at the time of delivery was 24years. High pregnancy rates among mothers in this age group could account for increased frequency of congenital anomalies in this age group.

Majority of the deliveries were in non tertiary care hospitals and only $25.67 \%$ were delivered in the tertiary care hospital. This is due to good referral system in the state were only antenatally detected anomalies which require tertiary care are referred. Anomalies detected in the antenatal period (32\%) in our study, were comparable to other studies. ${ }^{\text {[11] }}$

Mode of delivery in most of these children in our study was normal vaginal route and mean gestational age at delivery was 39 weeks. Most congenital anomalies are not affected by mode of delivery or timing of the birth. The most important issues in this decision are the individual lesion, associated anomalies, and presence of chromosomal abnormalities, preterm delivery, and efficacy of available postnatal therapies. ${ }^{[12]}$

In our study $81.3 \%$ of the anomalies were isolated and $15 \%$ were multiple anomalies, this is also seen in similar studies and literature. ${ }^{[13]}$ About $3.67 \%$ of the anomalies were a part of syndrome, sequence or associations. The most common system involved in our study was the genitourinary system, followed by gastrointestinal tract, head\& neck, respiratory and musculoskeletal system. The findings were different compared to other studies, were anomalies of the gastrointestinal tract and musculoskeletal system was more common. ${ }^{[7,14]}$ In our study it was found that among the genitourinary anomalies most common was ureteropelvic junction obstruction followed by vesicoureteric reflux. This finding seems to vary in various studies, in certain regions Posterior urethral valve, seems to be common, certain other region shows polycystic kidneys as most common anomaly. ${ }^{[15,16]}$ Among the gastrointestinal anomalies anorectal malformations were more common than other anomalies, this finding is also seen in similar studies. ${ }^{[14]}$ In both males and females, intermediate anorectal malformations were most common followed by low and high anomaly. Cleft lip and palate were the most common anomaly seen in head and neck. Of the anomalies of respiratory system congenital diaphragmatic hernia was the most common anomaly followed by trachea-esophageal fistula, in similar studies tracheoesophageal fistula was found to be more common. Majority of children underwent surgical correction. 59\% children had single surgery, 32.67\% children had multiple surgeries, which also included staged procedures. Most of the surgical complications were minor, only $10.67 \%$ children had major complications, shows that timely intervention can reduce morbidity.

\section{CONCLUSION}

Congenital anomalies are a major cause of hospital admissions in children of 
Sam Varkey et.al. Pattern of congenital overt and occult pediatric surgical anomalies in a tertiary care centre over 5 years.

all ages. Early diagnosis and surgical correction of the malformed babies reduces mortality and morbidity. Antenatal detection of anomalies helps in planning the postnatal management of correctable anomalies. It also helps in termination of fetus with lethal anomaly before attaining viability. All newborns should be examined for overt as well as occult congenital anomalies. More research is needed to determine the factors underlying the various types of congenital malformations. Pediatric surgical care is an essential component in the management of children with congenital anomalies.

\section{Conflict of Interest: There are no conflict of interest}

\section{Ethical Approval: Approved}

\section{REFERENCES}

1. Hudgins L, Cassidy SB, Martin RJ, et.al. Congenital anomalies; Neonatal-Perinatal Medicine $8^{\text {th }}$ ed. Philadelphia. MosbyElsevier; 2006: 561-568.

2. https://www.who.int/news-room/factsheets/ detail/congenital-anomalies.

3. Congenital malformations in K. Park's textbook of preventive and social medicine $22^{\text {nd }}$ edition. 2013; 533-34.

4. Chaturvedi P, Banerjee KS. Spectrum of congenital malformations in newborns from rural Maharashtra. Indian J Pediatr. 1989; 56: 501-7.

5. Bhat BV, Ravikumara M. Perinatal mortality in India- need for introspection. Indian J Matern Child Health 1996;7:31-3.

6. Bhide P, Gund P, Kar A (2016) Prevalence of Congenital Anomalies in an Indian Maternal Cohort: Healthcare, Prevention, and Surveillance Implications. PLoS ONE 11(11): e0166408. doi:10.1371/journal. pone. 0166408.

7. Golalipour MJ, Ahmadpour kacho M, Vakili MA, Congenital malformations at referral hospital in Gorgan, Islamic Republic of Iran. East Mediterr Health J 2005 jul;11(4):707-15.
8. https://www.cdc.gov/nchs/data/series/sr_21/ sr21_031.pdf

9. M Vrijheid, Helen Dolk, D stone. Socioeconomic inequalities in risk of congenital anomaly. Arch Dis Child: 10.1136/adc.82.5.349 on May 2000.

10. Harihar Sahoo, Paramita Debnath, Chaitli Mondal. Changing trends of consanguineous marriages in South India. JAAS doi 10.117/00219096211012017.

11. Gokulkrishna R,Nirmala P, Chandrashekar G. Incidence of antenatally detected congenital anomalies in a tertiary care hospital in a rural setting- A prospective observational study. Progressing aspects in pediatrics and neonatology ISSN: 26374722 published july 01/ 2020. doi 10.32474/PAPN 2020.02000144.

12. Charles M McCurdy, John W Seeds. Routes of deliveries of infants with congenital anomalies. Clinics in perinatology, $01 \mathrm{Mar}$ 1993, 20(1):81-106 https://doi.org/10.1016/ 50095-5108(1)30413-5

13. Gomella's Neonatology ( $8^{\text {th }} \& n b s p ; \quad$ ed.); Common multiple anomalies: syndromes, sequences and associations: chapter93.

14. Babita Jangra, Mahavir Singh, Kamal N Rattan et.al. Congenital anomalies in pediatric surgery in North India. African Journal of Pediatric surgery; 2014/volume11/issue1/page:39-43.

15. Kebede Mola, Damte Shimelis. Pattern and outcome of renal diseases in hospitalized children in Tikur Anbessa- specialized teaching hospital, Addis Abbaba, Ethiopia. Ethiop Med J 2016 jul;54(3):117-23.

16. You Lintain, Hsing Luh,Chin Yuang Lin. Incidence and risks of congenital anomalies of kidney and urinary tract in newborns. Medicine (Baltimore) 2016 feb:95(5)2659. doi10.1097MD0000000000002656.

How to cite this article: Sam Varkey, Aravind C. S, Reeti Rajan. Pattern of congenital overt and occult pediatric surgical anomalies in a tertiary care centre over 5 years. Gal Int $J$ Health Sci Res. 2021; 6(4): 16-20. DOI: https://doi.org/10.52403/gijhsr.20211004 